\title{
Are older drivers different in the US and Italy?
}

\author{
G. Fancello ${ }^{1}$, N. Stamatiadis ${ }^{2}$, E. Pani-Wilkinson ${ }^{3}$ \& P. Fadda ${ }^{1}$ \\ ${ }^{1}$ Cagliari University, Italy \\ ${ }^{2}$ Kentucky University, USA \\ ${ }^{3}$ American Consulting Engineers, USA
}

\begin{abstract}
The behavior of older drivers has been receiving increasing attention over the last few years in the safety community. Large numbers of over 65 year-olds continue to drive into their old age mainly because of the advances in medicine and a longer active working life. This paper aims to examine the potential driver behavior differences between two samples of older drivers from two countries (Italy and USA) with very different driving habits, driving regulations and road infrastructure conditions. In particular, we examined four maneuvers (merging from a ramp, changing lanes, turning left and night driving) for which interviewees were asked to describe how they would react. The data gathered were analyzed using multidimensional techniques that enabled to identify groups having homogeneous behavior in each sample. The findings indicate that drivers of the same age exhibit different driving habits and in different driving environments react differently and are thus confronted with different situations in terms of safety. This demonstrates that, generally speaking, the older drivers in US and Italy are similar but they have a different perspective of risk that varies depending on several factors including medical conditions, driving habits, driving conditions.
\end{abstract}

Keywords: older drivers, traffic safety, crashes.

\section{Introduction}

The behavior of over 65 year old drivers has become a major focus area of safety research in the past few years. Increased life expectancy, progress in medicine, provision of more work and non-work services for broad segments of the population have all led to a percentage and absolute increase in the number of active elderly. This has also a direct impact on their mobility needs. Nowadays 
we frequently call third age those 65 to $75-80$ year olds who are still active and self sufficient and fourth age the over 80 's who instead tend to spend less time outside the home.

Italian statistics (ISTAT) show that in 2001, the number of over 65-year olds in Italy accounted for $18.7 \%$ of the population as a whole, increasing to $23 \%$ calculated on an over- 18 basis. The percentages are similar in the US, where the figure for over 65 year olds is predicted to rise to $20 \%$ of the population between 2020 and 2030. The issue with these population increases is that elderly prefer their own car to fulfill their mobility needs; as everybody else does.

An analysis of accident data has revealed that the number of accidents caused by elderly drivers is, on average and per unit distance driven, actually lower than other age groups (Dissanayake and $\mathrm{Lu} \mathrm{[1]),} \mathrm{despite} \mathrm{reports} \mathrm{to} \mathrm{the} \mathrm{contrary,}$ which indicate an increase in the accident rates for 50 year olds and over (Broughton [2], Maycock [15]). It should be noted though that there are contrasting standpoints in the literature on whether elderly drivers are to be considered high risk. One side claims that they are not any worse than any other drivers for the following reasons:

1. in absolute terms older drivers do not represent a high risk group; by contrast as they recognize their own limitations and slower reactions, they tend to drive more cautiously and observe the rules of the road (Hakamies-Blomquist [3]);

2. in spite of their responsible behavior behind the wheel, there is an increase in the number of road accidents involving injuries to the elderly: this is to be attributed not, as mistakenly believed, to the higher accident rate, but to the greater physical fragility of over 65 year olds who are more likely to sustain injury in the event of an accident (Evans [4], Broughton [2]);

3. practically no driving under the influence of alcohol or drugs or falling asleep at the wheel rank very low in accidents caused by elderly people; similarly, very few older drivers are involved in single vehicle accidents (Hakamies-Blomquist [3]);

The other side notes that elderly drivers are indeed a high risk group and this is due to the smaller number of miles driven, chiefly for reasons associated with their mental and physical faculties. The reasons for this claim can be summed up as follows:

1. Analysis of age, gender and cohorts, indicated that middle age drivers are safer than younger drivers who, in turn, are safer than older drivers. Older male drivers are safer than older female drivers and more recent cohorts of older drivers are safer than more distant cohorts (Stamatiadis and Deacon [5]);

2. Elderly drivers are a high risk population because of the type of accidents that older drivers are usually involved. In fact, side impact crashes are twice as likely to occur with older drivers rather than younger drivers. Due to the severity of these types of crashes, it is generally harder for an older person to recover than a younger driver. (Staplin et al [16], Mitchell and Stamatiadis [6], Chandraratna et al [7]); 
3. There is a higher incidence of elderly drivers involved in accidents occurring in more complex and mentally demanding situations, such as for instance at junctions or slip roads., where the driver has to carry out several tasks simultaneously (merging into traffic flow, pedestrian crossings etc.). Recent studies have shown that high risk maneuvers include merging from a slip road into mainstream traffic, multi-lane driving and turning across traffic at unsignalized intersections (Fancello et al [8], Fancello [9], Daigneault et al [10]).

Over the last ten years, a great deal of attention has been focused on driver perception. Several studies have shown that mental and physical conditions, driving habits and behavior when performing certain maneuvers differ with age. In particular, the mental and physical faculties of over 65-year olds as well as their ability to concentrate behind the wheel deteriorate more rapidly, with the result that there is a greater likelihood of them having an accident caused by human error (Fancello et al [8], Hakamies-Blomquist [3], Voorhees [11]). And this is in spite of the fact that older people often drive "more cautiously" as they have more experience and are more aware of the potential hazards (Owsley et al [12]). It is for this reason that research in latter years has focused primarily on identifying active safety measures to assist older drivers, aimed at facilitating certain tasks and improving their performance, so as to avoid mishaps on the road. These measures concern above all restrictions and limits (in relation to certain diseases or visual impairments), support and assistance (driving classes and refresher courses covering particular kinds of maneuvers), redesigning the road system (in relation to the higher risk maneuvers), and in-vehicle driving aids (to be tested during simulator sessions (Hakamies-Blomquist [3], Parker et al [13], Lee et al [14]). However, since road infrastructure and driving regulations as well as driving habits and stereotypes differ from one country to another (Fancello et al [8]), clearly the safety measures identified are not generally applicable inasmuch as driver behavior differs precisely in relation to national regulations and driving stereotypes.

In this paper we have analyzed the results of a joint investigation conducted in two states in two countries, USA (Kentucky) and Italy (Sardinia), which have distinct difference in regard to roadway aspects and design as well as driving habits and rules. The objective of the work was to compare the behavior of elderly drivers in Kentucky and Sardinia and determine whether there are any differences between these two groups and whether they could be attributed to the roadway aspects, and driving habits and rules.

Even though the drivers tested here are residents of a specific region within their respective countries, most of the differences noted in their driving habits could be considered as indicative of all drivers in each country. These differences could be attributed to driving habits, roadway environments, vehicle types, legislation, and traffic enforcement levels. These results could provide a peek in the differences between drivers in the two countries, Italy and USA, but generalizations should be avoided and conclusions should be drawn carefully. The analysis results revealed that drivers behave differently and consequently in identifying driver support measures we have had to allow for the differences in driving habits and behavior standards. 


\section{Methodology}

The data collected were analyzed by means of multiple correspondence analysis (MCA) and cluster analysis (CA). These two techniques were chosen because: 1) they are among the best suited for questionnaire analysis; 2) they enable macro variables to be identified that, by limiting dimensional reduction, well describe the phenomenon; and 3) they are able to explore correlation among variables and identify homogeneous behavior based on the type of response (Bouroche et al [17], Diday et al [18]).

MCA involves dimensionality reduction by introducing factorial axes. An iterative procedure is used to define the axes (factors) that generate subspaces striking a good balance between the significance level of the information and the tolerated error value. The subspaces are defined by determining the factorial planes onto which the data are to be projected. The significance of the variables is evaluated by means of the test value (TV) parameter. The greater the absolute value of the TV the higher the significance is.

In cluster analysis, a hierarchical procedure is used based on the inertia criterion and the Ward method, whereby homogeneous individuals are classed into groups determined by evaluating their distances (it's an Euclidean distance between clusters or objects when forming the clusters). The different clusters representing homogeneous behavior, each characterized by TV's associated to the most significant variables, are then compared.

The above techniques were applied to both the US and Italian samples. Comparison of the results made it possible to identify common features and behavioral differences, including those that are not so evident and well-known.

\section{Data analysis}

The analysis concerned a total of 235 interviews, 81 conducted on residents in the Lexington area (KY - USA) and 154 on residents in the city of Cagliari (Italy). The sample was randomly chosen from among over 65-year olds, in possession of a valid driver's license. The first section of the questionnaire concerned background information, such as age and type of car owned, number of driving offences over the last few years, use of driver or passenger seatbelts. The second (medical) section contained questions about health status, the frequency of medical check-ups, the correct use of medication, corrective lenses. The other four sections concerned driving behavior when performing specific maneuvers: namely merging from a ramp, changing lanes, turning left and driving at night. Figure 1 shows an example of the questions contained in the questionnaire.

Because of the large number of variables to be handled jointly (95) several iterations were performed:

- $\quad$ the first, of a general nature, in which the differences in behavior between Italian and US drivers were determined, selecting in this case the 32 variables shown in Table 2 with their possible number of answers; 

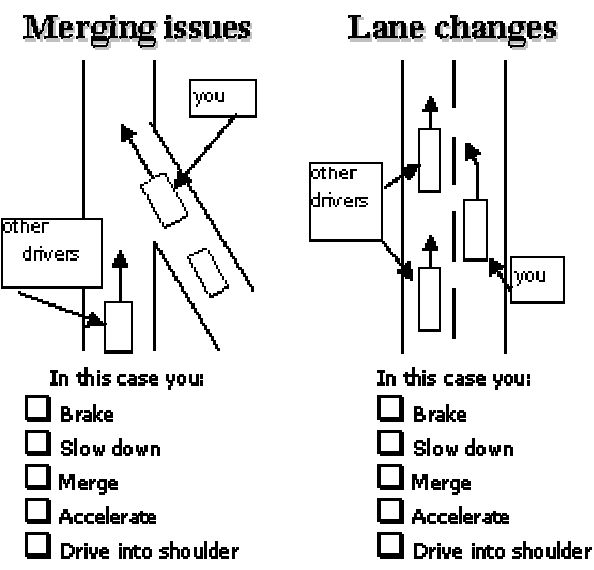

Left turning

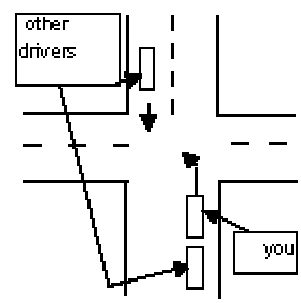

In this case you

$\square$ Brake'stop and tum

$\square$ slow down and tum

Decide not to tum and continue straight on

$\square$ Accelerate and tum

Figure 1: Example of questions.

Table 1: Variables considered in overall analysis of the phenomenon.

\begin{tabular}{|l|c|l|c|}
\hline \multicolumn{1}{|c|}{ Variable } & Answers & \multicolumn{1}{c|}{ Variable } & Answers \\
\hline Gender & 2 & Change lane & 6 \\
\hline Age & 4 & Information overload & 5 \\
\hline $\begin{array}{l}\text { Age drivers license } \\
\text { first issued }\end{array}$ & 6 & $\begin{array}{l}\text { Feel other motorists are } \\
\text { driving dangerously }\end{array}$ & 5 \\
\hline Vehicle usage & 4 & Drive at night & 5 \\
\hline Driving offences & 5 & Nervous driving at night & 5 \\
\hline $\begin{array}{l}\text { Annual medical check- } \\
\text { ups }\end{array}$ & 3 & Poor lighting & 5 \\
\hline Eye tests & 3 & $\begin{array}{l}\text { Confused by lane } \\
\text { markings }\end{array}$ & 5 \\
\hline $\begin{array}{l}\text { Description of health } \\
\text { status }\end{array}$ & 19 & $\begin{array}{l}\text { Alter route due to poor } \\
\text { lighting }\end{array}$ & 5 \\
\hline $\begin{array}{l}\text { Driving under the } \\
\text { influence of prescribed } \\
\text { medication }\end{array}$ & 5 & $\begin{array}{l}\text { Alter route due to poor } \\
\text { road markings }\end{array}$ & 5 \\
\hline $\begin{array}{l}\text { Use of corrective } \\
\text { lenses for driving }\end{array}$ & 6 & $\begin{array}{l}\text { Slow down to read road } \\
\text { signs }\end{array}$ & 5 \\
\hline $\begin{array}{l}\text { Muscle pains or } \\
\text { fatigue while driving }\end{array}$ & 5 & $\begin{array}{l}\text { Difficulty in turning at } \\
\text { unsigned junction }\end{array}$ & 3 \\
\hline Merging & 6 & Turning at junction 64 & 4 \\
\hline $\begin{array}{l}\text { Driving on freeways } \\
\text { or non-urban roads }\end{array}$ & 5 & $\begin{array}{l}\text { Judge speed of } \\
\text { oncoming traffic }\end{array}$ & 5 \\
\hline $\begin{array}{l}\text { Feel road markings } \\
\text { and signs inadequate }\end{array}$ & 5 & $\begin{array}{l}\text { Alter route to avoid } \\
\text { turning }\end{array}$ & 5 \\
\hline $\begin{array}{l}\text { See signs at last } \\
\text { moment }\end{array}$ & 5 & $\begin{array}{l}\text { Difficulty in turning in } \\
\text { daily traffic }\end{array}$ & 5 \\
\hline Do not drive at night & 5 & Hazardous situation & 5 \\
\hline
\end{tabular}


- $\quad$ another four iterations for each of the specific maneuvers merging on a ramp, multi-lane driving, turning left at an unsignaled intersection and night driving in which the specific variables of the relative questionnaire sections were used.

For brevity, the procedure followed for the first iteration is reported here in its entirety, while for the other four only the final results are described.

\section{Results}

\subsection{Multiple correspondence analysis}

Since the results are represented in a matrix with 235 rows (interviews) and 95 columns (questions), multiple correspondence analysis was employed to assist in understanding the behavior of the respondents. Analysis of the first seven factorial axes (which indicate the grouping of the drivers based on similarity of their answers) determined in the MCA, along with the relative eigen values (Table 3), reveals that there are overall differences between the responses of the participants in the two countries. For the US respondents, the first five axes already yield $36.07 \%$ explanation of the phenomenon, while all seven axes are not sufficient to attain the same level of explanation for the Italian respondents. This means that the US sample exhibits a more homogeneous and stable behavior than the Italian sample because it attained an explanatory value of $43.12 \%$ for the 7 axes.

Table 2: $\quad$ Seven most significant factorial axes for US and Italian data.

\begin{tabular}{|c|c|c|c|c|c|c|}
\hline & \multicolumn{3}{|c|}{ Italy } & \multicolumn{3}{c|}{ USA } \\
\hline Axis & $\begin{array}{c}\text { Eigen- } \\
\text { Value }\end{array}$ & Percent & $\begin{array}{c}\text { Cumulative } \\
\text { Percent }\end{array}$ & $\begin{array}{c}\text { Eigen- } \\
\text { Value }\end{array}$ & Percent & $\begin{array}{c}\text { Cumulative } \\
\text { Percent }\end{array}$ \\
\hline 1 & 0.2762 & 8.84 & 8.84 & 0.5166 & 13.25 & 13.25 \\
\hline 2 & 0.1779 & 5.69 & 14.53 & 0.3163 & 8.11 & 21.36 \\
\hline 3 & 0.1399 & 4.48 & 19.01 & 0.2297 & 5.89 & 27.24 \\
\hline 4 & 0.1032 & 3.30 & 22.31 & 0.1900 & 4.87 & 32.12 \\
\hline 5 & 0.0907 & 2.90 & 25.22 & 0.1543 & 3.96 & 36.07 \\
\hline 6 & 0.0840 & 2.69 & 27.91 & 0.1464 & 3.75 & 39.83 \\
\hline 7 & 0.0812 & 2.60 & 30.50 & 0.1283 & 3.29 & 43.12 \\
\hline
\end{tabular}

The next step involved the examination of the contribution values for each variable in the first five factorial axes. This step identified some significant factors that differentiate the US and Italian samples. For the Italian data, the first axis is determined by variables indicating that older drivers in any case prefer to continue driving even though they change their behavior (demonstrated by variables such as slow down to read road signs, alter route due to poor lighting and alter route due to poor road markings). The second axis on the other hand is defined by variables such as confused by lane markings, nervous driving at night, difficulty in turning at unsigned junction, and feel other motorists are driving dangerously, indicating that the elderly admitted experiencing 
difficulties driving. For the US sample on other hand, the variables contributing to determining the first two axes take the reverse order: the first axis comprising those variables indicative of the difficulties older people encounter in driving, the second being defined essentially by variables associated with a change in driving behavior.

The analysis of the contribution of the variables only provides a quantitative evaluation of the factorial axis structure and some preliminary indications as to the differences between the two samples (older US drivers appear to take a more prudent approach to driving). It does not however provide sufficient information for making a clear distinction between behavior and actions of the two samples. This requires an analysis of the information contained in each axis. The first factorial axis for the US sample is characterized by variables relating to the situation where no particular driving difficulties are encountered. A clear distinction can be observed between modalities with "no answer" whose significance is defined by a TV of 8.52 , and those where the behavior is unconditioned, respondents having ticked "never" to the questions "How often do you feel nervous driving at night" (TV=3.36), "how often do you alter your route to avoid turning left at unsignalized intersections?" (TV=3.46), "how often do you have a difficult time judging speed of opposing traffic when trying to turn left?" (TV=3.16). Again on the first axis a weaker correlation can be observed between these variables and cautious driving behavior, such as frequently slowing down when approaching road signs, $(\mathrm{TV}=2.02)$ and feeling other vehicles are a danger ( $\mathrm{TV}=2.28)$.

Looking at the second axis, a correlation exists between the modalities concerning the response "never" to the questions "Do you continue to drive at night?" (TV=6.75), "how often do you drive on highways or interstates?" $(\mathrm{TV}=8.55)$, and those concerning mental overload of information when attempting to change lanes $(\mathrm{TV}=3.23)$, constant difficulties in turning left $(\mathrm{TV}=3.46)$ and the modalities for use of corrective lenses while driving $(\mathrm{TV}=5.19)$ as well as older drivers in the 76-80 age group $(\mathrm{TV}=2.54)$. Lastly, the third axis shows the relationship between the modalities concerned with recognizing hazardous situations in urban traffic ( $\mathrm{TV}=-4.31$ ), and difficulties in making left turns (TV=-2.86).

In summary, the analysis of the sample of older US drivers showed that they, in general, are careful and cautious behind the wheel, due largely to the fact that these motorists usually observe the rules of the road and conform to stereotypes of road safety education. This is also clearly shown for respondents who reported no particular difficulties when driving, and did not use the car in less than optimal driving conditions (poor visibility, dark, heavy traffic, etc). The analysis of the Italian data show for the first axis the modalities "no answer" to the questions whether drivers had difficulties making out lane markings ( $T V=$ 11.36), felt nervous driving at night $(\mathrm{TV}=-10.78)$, felt lighting was poor ( $\mathrm{TV}=$ 10.20 ) and altered their route due to poor lighting or to avoid turning left (TV=10.99), to be significant.

The variables for which the respondents indicated "never" also contribute significantly to determining the first axis. In particular, these deal with questions 
concerning alteration of route due to poor lighting $(\mathrm{TV}=5.93)$ or inadequate road signs or markings $(\mathrm{TV}=5.33)$, slowing down to read road signs or markings $(\mathrm{TV}=4.88)$, feeling nervous about driving at night $(\mathrm{TV}=4.61)$, and confusion over lane markings ( $\mathrm{TV}=4.43)$. Whereas the first axis for the Italian sample is fairly similar to the US one, the second axis is characterized by the modalities "occasionally" or "sometimes" associated with the variables such as driving at night (TV=-6.60), information overload of when changing lanes ( $\mathrm{TV}=-6.42$ ), nervousness driving at night $(\mathrm{TV}=-6.23)$, feeling others are driving dangerously $(\mathrm{TV}=-5.76)$. In the opposite part of the second axis on the other hand, the modalities regarding no difficulties experienced in turning at intersections $(\mathrm{TV}=5.80)$ in making out lane markings $(\mathrm{TV}=5.62)$, or in feeling others drove dangerously $(\mathrm{TV}=4.76)$ were found to be highly significant. This indicates the self-confidence gained through long experience behind the wheel of the drivers who responded in this way.

The comparison of the factorial axes for the two samples shows that for the US drivers, variables relating to more cautious behavior are in any case associated with variables indicating a less inhibited driving behavior, suggesting, as already mentioned, that US motorists take a more prudent approach to driving, recognizing their own limits. By contrast, the Italian data show that the variables indicating no difficulties in performing certain maneuvers are associated with other variables that conversely are indicative of episodes of mental overload of information and difficulties when driving. This demonstrates that Italian drivers tend to be slightly less responsible and less inhibited by their own limits. The cluster analysis enabled to recognize type-profiles of the respondents for the different maneuvers investigated, identifying homogeneous groups partly or wholly characterized by the most significant variables resulting from the MCA.

\subsection{Cluster analysis}

Cluster analysis of the questionnaire responses allowed the identification of homogeneous groups among the respondents: the larger the number of identical answers, the greater the probability that individuals will belong to the same group. Several class partitions have been explored and evaluated using the difference in responses between the representative partition and the described phenomenon. The final choice falls on the most significant partition that enables to better identify the different characteristics of the respondents.

The overall analysis of the two samples of interviewees, from Sardinia and Kentucky, identified three different groups that were common to both samples:

- Group A: Sometimes encountered difficulties driving

- Group B: Occasionally encountered difficulties driving

- Group C: Never encountered difficulties driving

Regarding the US sample, only $20.6 \%$ of interviewees reported never having difficulties driving, against $34.6 \%$ who sometimes and $21.3 \%$ who occasionally experienced difficulties. By contrast, older Italian drivers were found to be more confident, $30.5 \%$ of the sample stating they never experienced difficulties driving, compared to a total of roughly $47 \%$ who did $(40.9 \%$ sometimes and 
$6.5 \%$ occasionally). Even though the analysis produced fairly similar results for the two samples, the most significant aspect that emerged from the comparison is the more prudent approach to driving exhibited by US drivers. They appear to be more aware of their limitations compared to Italian drivers who, by contrast, are less apprehensive about getting behind the wheel.

The next step involved the analysis of the single maneuvers, i.e. merging from a ramp, changing lanes, turning left and night driving. After several iterations we opted to use just active variables, 10 for the background and medical information, 11 for merging issues, 8 for lane changes, 5 for left turning maneuvers and 6 for night driving. The multiple correspondence analysis, not shown here for the sake of brevity, revealed that the most significant variables for each maneuver are in fact those characterizing the different ways drivers behave when performing such maneuvers. The variables are those shown in the cluster analysis. For all the cases described here, overall significance levels of the groups range from 85 to $95 \%$.

Comparison of the US and Italian data reveals that drivers behave differently when merging into mainstream traffic from a ramp. $50.62 \%$ of US drivers accelerate when merging, while group $B$, representative for its size $(19.7 \%)$ represents drivers who do not change their speed when merging. This means that a high percentage of drivers behaves confidently, maintaining a steady pace, and does not perceive other drivers as hesitant or dangerous. The groups identified for the Italian sample on the other hand were observed to behave differently. As much as $33.77 \%$ of the sample braked when merging with mainstream traffic, while $19.44 \%$ continuously changed their speed. This suggests hesitancy and erratic behavior, posing a hazard to other drivers. Here again Italian drivers were found to be less confident. The groups used here are:

- $\quad$ Group A: Merge breaking

- Group B: Merge without changing speed

- Group C: Merge changing speed continuously

- Group D: Merge forcefully

- $\quad$ Group E: Merge accelerating (US sample only)

- Group F: Merging slowing down (Italian sample only)

As for changing lanes, in the US sample the largest size group (46.91\%) is represented by respondents who report no problems when changing lanes, while $19.75 \%$ wait for the approaching vehicle to pass and then change lanes safely. As much as $78.67 \%$ of the Italian sample waits for the approaching vehicle to pass, delaying the maneuver, which though associated with more cautious behavior, in many cases can obstruct the traffic flow. Other examples of Italian driving behavior included drivers slowing down to wait for approaching vehicles to pass or even braking or stopping altogether $(10.14 \%)$, risking multiple pile-ups. The groups used here were as follows:

- Group A: Wait for vehicle to pass

- $\quad$ Group B: Change lane (US sample only)

- Group C: Remain in lane (US sample only)

- Group D: Slow down

- Group E: Brake and then stop (Italian sample only) 
For left turning maneuvers at intersections, two significant groups were identified for the US sample, with $62.96 \%$ of respondents stopping and then proceeding to make the left turn without any difficulty, while $28.40 \%$ slowed down or quickly crossed the intersection. This behavior can probably be explained by the fact that the US highway code regulating right of way at intersections states that the first vehicle to arrive is the first to pass. In Italy motorists are obliged to give way to traffic from the right, but as the data show, older drivers do not always observe this rule. In fact the table concerning left turns shows that only $8.4 \%$ of respondents stop and then proceed to turn, $39.5 \%$ accelerate without difficulty and $43.5 \%$ stop and then complete the maneuver. The following groups were used here:

- Group A: Slow down

- $\quad$ Group B: Stop and proceed to turn with no difficulties

- Group C: Accelerate - no difficulties (Italian sample only)

As for night time driving, the major difference between the Italian and US sample is the large number of Italian drivers who do not drive at night (18.18\%), compared to a negligible number of US drivers. In the latter case the sample was divided into drivers who never $(22.22 \%)$ and those who sometimes $(67.8 \%)$.encountered difficulties. By contrast the Italian sample was divided up into two major groups, those who reported never experiencing problems with night time driving (42.21\%) and those who sometimes had problems $(35.5 \%)$. For both samples the major difficulties were to be attributed to visibility due to age-related deterioration in eyesight. The groups used here are the following:

- Group A: Some difficulties

- $\quad$ Group B: No difficulties

\section{Discussion}

Some fundamental points emerged from the analysis presented in the preceding:

- Overall, Italian and US drivers were found to behave fairly similarly, though older drivers in the USA tend to have a slightly more prudent approach to driving than their Italian counterparts. Comparison of the data show that the groups identified and their relative specific variables are fairly comparable. Thus this would tend to confirm that the absence of significant behavioral differences between the samples.

- $\quad$ The analysis of the specific maneuvers indicated substantial differences in driving behavior and action taken when performing a specific task between the tow samples.

- $\quad$ For the merging from a ramp maneuver, the most significant difference between the two samples is that older drivers in the USA behave in a more consistent and self-assured manner, 50\% accelerating when merging and $19.7 \%$ merging without changing speed. By contrast, the Italian drivers were found to be less confident, 33\% braking when merging, $19.4 \%$ changing speed continuously and $21 \%$ proceeding slowly. In terms of road characteristics, this behavior can be explained by the fact that on many Italian roads, especially minor roads, no provision is made for 
acceleration lanes for safe merging with the result that in heavy traffic drivers have to force their way into mainstream traffic. Consequently, if the driver is unable to accurately judge the speed of vehicles approaching from behind because of impaired eyesight or mental fatigue, the risk of collision increases.

- $\quad$ For the changing lanes maneuver, the differences in behavior displayed by older drivers in the two countries are clearer. While US drivers perform well for this type maneuver, the same cannot be said of Italian drivers. In fact, half of the US drivers reported having no difficulty in changing lanes whereas $78.6 \%$ of Italian drivers stated they waited for the vehicle approaching from behind to pass before changing lane. This can be explained by the fact in the USA motorists are allowed to drive alongside other vehicles on multilane highways and as a result are more accustomed to changing lanes safely. In Italy, on the other hand, where this is not allowed, drivers take a more cautious approach, tending in any case to keep to the right.

- $\quad$ For the left turn maneuvers, again substantial differences were observed between the two samples. The most significant difference is that in all traffic situations US drivers stop before negotiating the left turn, whereas a large percentage of Italian drivers (almost 40\%) accelerate, even if oncoming vehicles are present, and turn. This difference may be attributed to the fact that in the USA motorists are obliged to stop before turning across traffic, while in Italy the give way rule applies. Also, Italian roads often lack dedicated turning lanes or protection from vehicles approaching from behind or oncoming traffic.

- $\quad$ For night driving, older drivers were found to behave fairly similarly in the two countries, but again US drivers are taking a more prudent approach compared to their Italian counterparts. In fact, $42.2 \%$ of Italian drivers declared they did not encounter problems driving at night compared to $22 \%$ of US drivers.

In conclusion, driver stereotypes and driving environment understandably play a major role in assessing driving behavior and the results of the present analysis demonstrate that the assumption that older drivers generally experience difficulties when performing complex maneuvers such as turning left across traffic or on-ramp merging is misconceived. On the contrary, the findings indicate that the degree of difficulty experienced by older drivers differs depending on their driving habits and the driving environment.

\section{References}

[1] Dissanayake S., Lu J.J. (2002) "Factors influential in making an injury severity difference to older drivers involved in fixed object-passenger car crashes" Accident Analysis and Prevention, 34, 609-618.

[2] Broughton L. (1988) "The Variation of Car Drivers' Accident Risk with Age" Transport Research Laboratory Report RR135. TRL, Crowthorne, UK. 
[3] Hakamies-Blomqvist L. (2004) “Older drivers - a review" VTI rapport 497A - Swedish National Road and Transport Research Institute.

[4] Evans L. (1991) "Traffic Safety and the Driver" Van Nostrand Reinhold, New York.

[5] Stamatiadis N., Deacon J. A. (1995) "Trends in highway safety: effects of an aging population on accident propensity" Accident Analysis and Prevention, 27, 443-459.

[6] Mitchell L. and Stamatiadis N. (2002) Traffic Maneuvers of Elderly: Their Viewpoint and Perspective - 2002 Society of Automotive Engineers, Inc

[7] Chandraratna S., Michell L., Stamatiadis N. (2002) "Evaluation of the transportation safety needs of older drivers" Dept. of Civil Engineering, University of Kentucky.

[8] Fancello G., Pani E., Fadda P. (2003) "Road safety on elderly drivers: an experimental human factors analysis" XXIInd PIARC World Road Congress Proceedings, Durban 19-25 October 2003.

[9] Fancello G. (2004) "Analisi sperimentale degli incidenti causati da guidatori anziani: un approccio multidimensionale”, Ingegneria Ferroviaria, 59(1), 47-56.

[10] Daigneault G., Joly P., Frigon J.Y. (2002) "Previous convictions or accidents and the risk of subsequent accidents of older drivers" Accident Analysis and Prevention, 34, 257-261.

[11] Voorhees A.M. (2005) "Safe Mobility at Any Age Policy Forum Series Final Report (draft)" Alan M. Voorhees Transportation Center, Edward J. Bloustein School of Planning and Public Policy, Rutgers, The State University of New Jersey, New Jersey Foundation for Aging.

[12] Owsley C., Stalvey B.T., Phillips J.M. (2003) "The efficacy of an educational intervention in promoting self-regulation among high-risk older drivers" Accident Analysis and Prevention, 35, 393-400.

[13] Parker D., McDonald L., Rabbitt P., Sutcliffe P. (2003) "Older drivers and road safety: the acceptability of a range of intervention measures" Accident Analysis and Prevention, 35, 805-810.

[14] Lee H.C., Cameron D., Lee A.H. (2003) "Assessing the driving performance of older adult drivers: on-road versus simulated driving" Accident Analysis and Prevention, 35, 797-803.

[15] Maycock G. (1996) "The Safety of Older Car Drivers in the European Union" AA Foundation for Road Safety Research. AA Foundation for Road Safety Research, Basingstoke, England.

[16] Staplin, L., Lococo, K., Byington, S., \& Harkey, D. (2001). Guidelines and recommendations to accommodate older drivers and pedestrians (Report No. FHWA-RD-01-051). Virginia, USA: Federal Highway Administration (FHWA).

[17] Bouroche J.M. e Saporta G., 1980, L'analyse des donnèes, Presse Universitaires de France, Parigi

[18] Diday, E., Lemaire, J., Pouget, J., Testu, F.: Elements d'analyse de donnees. Paris, Bordas, 1982 